\title{
IODP workshop: tracking the Tsunamigenic slips across and along the Japan Trench (JTRACK)
}

\author{
J. D. Kirkpatrick ${ }^{1}$, M. Strasser ${ }^{2}$, S. Kodaira ${ }^{3}$, J. Sample ${ }^{4}$, J. Mori ${ }^{5}$, and S. Saito ${ }^{6}$ \\ ${ }^{1}$ Department of Geosciences, Colorado State University, 1482 Campus Delivery, Fort Collins, CO 80523, USA \\ ${ }^{2}$ Geological Institute, ETH Zurich, NO G 46, Sonneggstrasse 5, 8092 Zurich, Switzerland \\ ${ }^{3}$ Research and Development Center for Earthquake and Tsunami, Japan Agency for Marine-Earth Science and \\ Technology, 3173-25 Showa-machi, Kanazawa-ku, Yokohama 236-0001, Japan \\ ${ }^{4}$ School of Earth Sciences and Environmental Sustainability, Northern Arizona University, 602 S Humphreys, \\ Flagstaff, AZ 86011, USA \\ ${ }^{5}$ Disaster Prevention Research Institute, Kyoto University, Gokasho, Uji, Kyoto 611-0011, Japan \\ ${ }^{6}$ Research and Development Center for Ocean Drilling Science, Japan Agency for Marine-Earth Science and \\ Technology, 2-15 Natsushima-cho, Yokosuka, 237-0061, Japan
}

Correspondence to: J. D. Kirkpatrick (james.kirkpatrick@ colostate.edu)

Received: 26 October 2014 - Revised: 7 January 2015 - Accepted: 13 January 2015 - Published: 29 May 2015

1

\section{Introduction}

Subduction zones produce the world's largest and most destructive earthquakes. Hazards associated with these events include strong ground shaking and, when the seafloor is displaced by shallow earthquake slip, tsunamis can occur. Among the global efforts to mitigate earthquake hazards, investigations and resources for understanding the causes and effects of tsunamis have been relatively few compared to the many studies of strong earthquake shaking. Yet worldwide over the last decade, nearly a third of the loss of human life from earthquakes is attributed to tsunamis $(\sim 247000$ from tsunamis and $\sim 535000$ from earthquake shaking for 2002 to 2012). Understanding the dynamic processes and properties that control earthquake and tsunami occurrence is one of the main themes of the International Ocean Discovery Program Science Plan for 2013-2023.

Mechanical models of subduction zones often include a stable region at shallow depth on the plate boundary interface where earthquake nucleation is inhibited and relative plate motion is accommodated by aseismic slip (e.g., Sholz, 1998; Bilek and Lay, 2002; Wang and $\mathrm{Hu}, 2006)$. The $2011 M_{\mathrm{w}} 9.0$ Tohoku-Oki earthquake challenged these models. Slip during the earthquake was greatest at shallow depth near the trench, with most estimates indicating $50-80 \mathrm{~m}$ displacement, the largest ever recorded (Ide et al., 2011; Ito et al., 2011; Lay et al., 2011; Yue and Lay, 2011). Bathymetric surveys be- fore and after the earthquake show that the rupture breached the seafloor (Fujiwara et al., 2011). As a result of the unprecedented shallow slip, the tsunami generated by the event overwhelmed harbor tsunami walls and coastal berms and inundated Honshu, causing thousands of casualties and billions of dollars of damage in northern Japan.

Prior to 2011, the long historical and instrumental records available in Japan led most researchers to anticipate that the largest earthquake that would occur in the region would be about $M_{\mathrm{w}}$ 9.0. Previous tsunamigenic earthquakes recorded along the Japan Trench include the 1896 Sanriku and 1677 Enpou Boso earthquakes that occurred on the northern and southern portions of the margin, respectively (Tanioka and Gusman, 2012; Fig. 1). However, the Tohoku-Oki earthquake demonstrated that our relatively short instrumental and historical records are inadequate to fully characterize the complex and multi-scale seismic behavior of subduction zones. For example, the 2011 rupture extended $500 \mathrm{~km}$ along the Japan Trench and re-ruptured several regions that had experienced smaller events in the past century. If the 2011 event is representative of general subduction zone behavior, tsunamigenic extreme events with very long recurrence intervals could be characteristic of subduction margins globally.

The Integrated Ocean Drilling Program (IODP) Expedition 343/343T sailed 1 year after the 2011 Tohoku-Oki earthquake to investigate the conditions and processes that facilitated the large, shallow slip (Chester et al., 2013a). During 


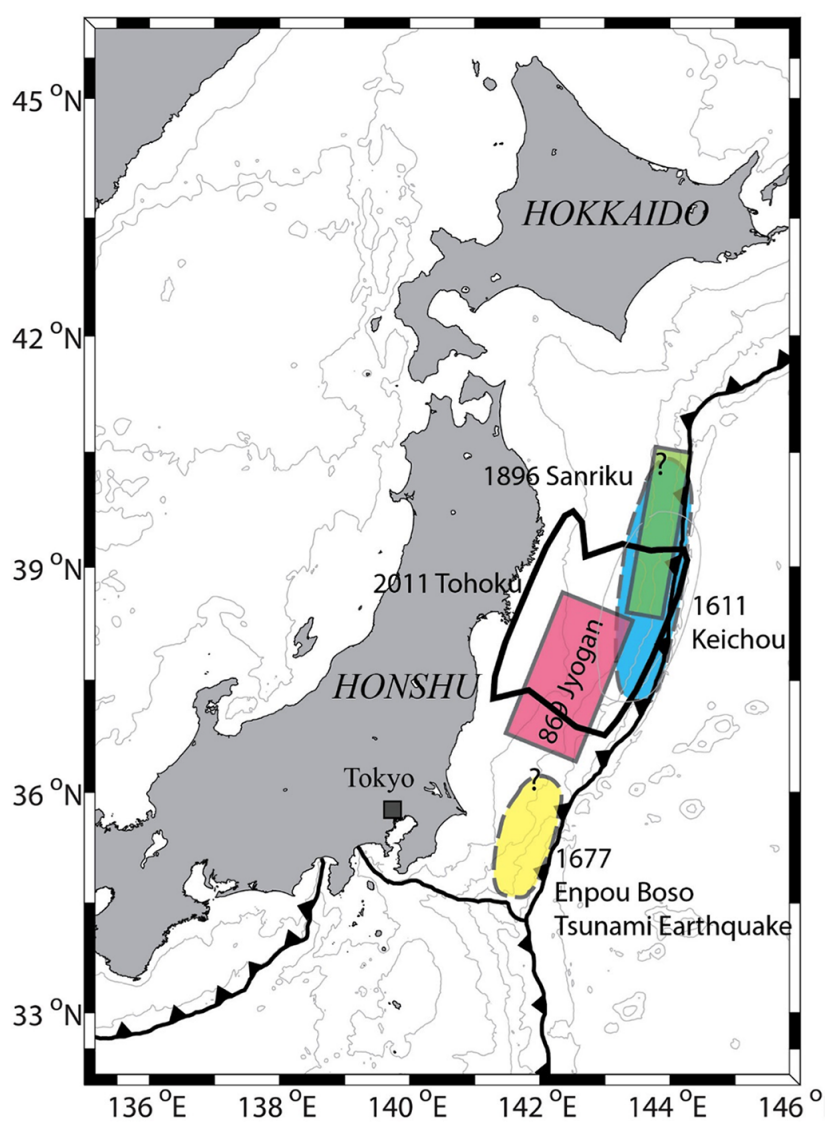

Figure 1. Map of the Japan Trench region showing historical tsunamigenic earthquake rupture areas (Hatori, 2003; Tanioka and Gusman, 2012; Sawai et al., 2012).

Exp. 343/343T, D/V Chikyu drilled three holes to around $840 \mathrm{~m}$ b.s.f. in a rapid response fault drilling campaign (the Japan Trench Fast Earthquake Drilling - JFAST - project). The success of Exp. 343/343T illustrates that the deep Japan Trench and 2011 earthquake rupture are potential targets for further scientific drilling research, and motivated the preproposal Tracking the Tsunamigenic slips Across and Along the Japan Trench (JTRACK): Investigating a new paradigm in tsunamigenic megathrust slip with very deep water drilling using the D/V Chikyu (IODP Proposal 835 Pre).

The JTRACK pre-proposal aimed to build upon the results from Exp. 343/343T by targeting the following overarching scientific objectives:

1. Understand the variations of physical and chemical properties of sediments and fluids of the near-trench megathrust that enable huge fault displacements and generate very large tsunamis.

2. Develop and implement new methods for determining the recurrence of giant tsunamigenic earthquakes in the sediment record of the trench fill.
JTRACK was developed to focus on the exceptionally well-instrumented Japan Trench subduction margin where tsunamigenic earthquakes are known to have occurred in 1677, 1896 and 2011 and historical and instrumental records show thirteen $M 7$ and five $M 8$ earthquakes over the last 400 years, in addition to the $2011 M 9$ event and its aftershock sequence (e.g., Hashimoto et al., 2009; Kanamori et al., 2006). This report summarizes the outcomes of a workshop to discuss the scientific goals of the JTRACK project.

\section{Lessons from Expedition 343/343T}

During Exp. 343/343T the D/V Chikyu penetrated and partially sampled the rupture zone of the 2011 earthquake (Chester et al., 2013a). Drilling in ultra-deep water depths of nearly $7 \mathrm{~km}$, logging while drilling (LWD) data were collected, cores recovered from targeted intervals, and a borehole observatory for long-term monitoring of formation temperatures was installed (Chester et al., 2013a; Taira et al., 2014). LWD data and cores recovered from depths down to $\sim 840 \mathrm{~m}$ b.s.f. defined the location and composition of the plate boundary fault (Chester et al., 2013b; Kirkpatrick et al., 2015). Temperature data from the observatory installed during Expedition 343T and recovered 9 months later by R/V Kairei showed a thermal anomaly at the megathrust horizon, which was used to infer a very low dynamic friction coefficient of 0.08 (Fulton et al., 2013), consistent with lab measurements of the frictional properties of core samples at seismic slip velocities (Ujiie et al., 2013). These results were made possible by the deep water drilling capabilities of $\mathrm{D} / \mathrm{V}$ Chikyu, and suggest that the resistance to slip on the fault near the trench during the earthquake was minimal.

\section{JTRACK workshop goals}

The IODP workshop, Tracking the Tsunamigenic slips Across and Along the Japan Trench (JTRACK): Investigating a new paradigm in tsunamigenic megathrust slip with very deep water drilling using the $\mathrm{D} / \mathrm{V}$ Chikyu, was held in Tokyo, 15-17 May 2014. Attended by $\sim 70$ scientists from 7 countries and 29 organizations or institutions, the workshop was sponsored by the National Science Foundation U.S. Science Support Program (USSSP), the Japan Agency for Marine-Earth Science and Technology (JAMSTEC) and the European Consortium for Ocean Research Drilling (ECORD). Tokyo was chosen as the location for the workshop because of the proximity to the Japan Trench and to emphasize the ongoing scientific community's response to the devastating 2011 Tohoku-Oki earthquake and tsunami.

The aim of the workshop was to bring together a diverse group of scientists to discuss and develop a plan for scientific drilling in the Japan Trench to establish the seismogenic and tsunamigenic history and potential of the shallow portion of the subduction zone. Building upon the recommendations by 
the science evaluation panel (SEP) from the JTRACK preproposal, the workshop goals were to (1) prioritize the key questions regarding the mechanical behavior of the fault and surrounding rocks, and (2) to develop plans for how to answer those questions with a coordinated program of deep water drilling and complementary giant-piston coring. Following talks that reviewed the instrumental and historical records of earthquakes along the Japan Trench and presented updates on the recent results from Exp. 343, participants worked in breakout groups to address goal (1). Breakout groups were based loosely around the scientific themes of mechanics of faulting, fluid geochemistry and microbiology, borehole logging, long-term monitoring, paleoseismology and geophysical site characterization. Reports from the breakout groups were made and discussed by the workshop as a whole. The breakout groups were then charged with developing strategies for how to address the questions prioritized by the workshop.

\section{Recommendations of the workshop}

\subsection{Deep-sea drilling to investigate the 2011 Tohoku-Oki rupture}

Overall, the JTRACK participants agreed that the Japan Trench, and specifically the 2011 Tohoku-Oki rupture are outstanding targets to generally investigate earthquake mechanics and subduction zone processes. The $M_{\mathrm{w}} 9.02011$ earthquake presents a unique opportunity to investigate a tsunamigenic earthquake, with results likely to contribute to an improved understanding of the hazard from shallow subduction zone slip along margins globally. Advantages of drilling at the Japan Trench include the extensive preexisting site characterization information (high-resolution seismic surveys, extensive bathymetric data and planned offshore GPS and OBS (ocean bottom seismometer) deployments), and the success of Expedition 343/343T that demonstrated the viability of drilling in extremely deep water.

The JTRACK pre-proposal included plans to investigate the rupture areas of three known historical tsunamigenic events: the 2011 Tohoku-Oki, 1896 Sanriku and 1677 Enpo Boso earthquakes. One key outcome from the JTRACK workshop was that such an extensive list of drilling targets would be unfeasible for one IODP proposal, and the participants agreed that the highest priority should the 2011 earthquake. The causes of the extraordinary slip near the trench during the 2011 Tohoku-Oki earthquake remain enigmatic, and to build upon results from Expedition 343/343T, it was agreed that the controls on rupture propagation and slip near the trench would be best established by targeting two areas of the rupture, one that underwent very large slip and one where the coseismic slip was relatively small. In combination with high-resolution seismic surveys, this strategy could allow potential lithologic, structural and hydrological controls on slip to be evaluated.
A series of interrelated questions were developed at the workshop that address the physical conditions, material properties and processes that drive shallow slip:

- How does the presence of frictionally weak, velocityweakening pelagic clay in the incoming plate influence the variable seismic behavior of the plate boundary?

- Is it possible to correlate the seismogenic behavior of the margin with variations in the stratigraphy of the input section?

- Are there differences in fault characteristics in regions that rupture in tsunamigenic earthquakes compared to great earthquakes?

- Are the materials in and around the fault zone capable of storing significant elastic strain between great earthquakes?

- What are the permeability values of rocks in and around the fault zone and how do they contribute to fluid flow and maintenance of fluid pressures and reduction in effective stress in the fault zone?

- Is there proxy evidence for repeated large slip at shallow depths on the plate boundary décollement?

- What is the shear strength and consolidation history of slope sediments and how do they contribute to slope failure during seismic activity?

- How quickly does the plate boundary fault recover and start to build up stress again after a great earthquake?

- How is the recovery process related to the amount of coseismic slip and stress drop?

Pursuing these questions will require acquisition of multiple data sets. The drilling strategy outlined during the workshop includes two transects perpendicular to the Japan Trench at latitudes corresponding to the region of maximum slip of the 2011 Tohoku-Oki earthquake and where the slip was substantially lower. Both transects have three sites (Fig. 2) which include boreholes on the inner trench slope, reference sites on the incoming plate and basin drilling for sediment records (see Sect. 4.2). At the inner trench slope and reference sites, LWD measurements and cores will be used to define the lithology, structure, stress state and mechanical and hydrological properties of the frontal prism, subducted plate and input section. In addition, a long-term borehole observatory to monitor the subsurface pore pressure and temperature field over time is planned at one inner trench slope location. This drilling strategy was designed to enable the work to be carried out in several short-duration expeditions. 


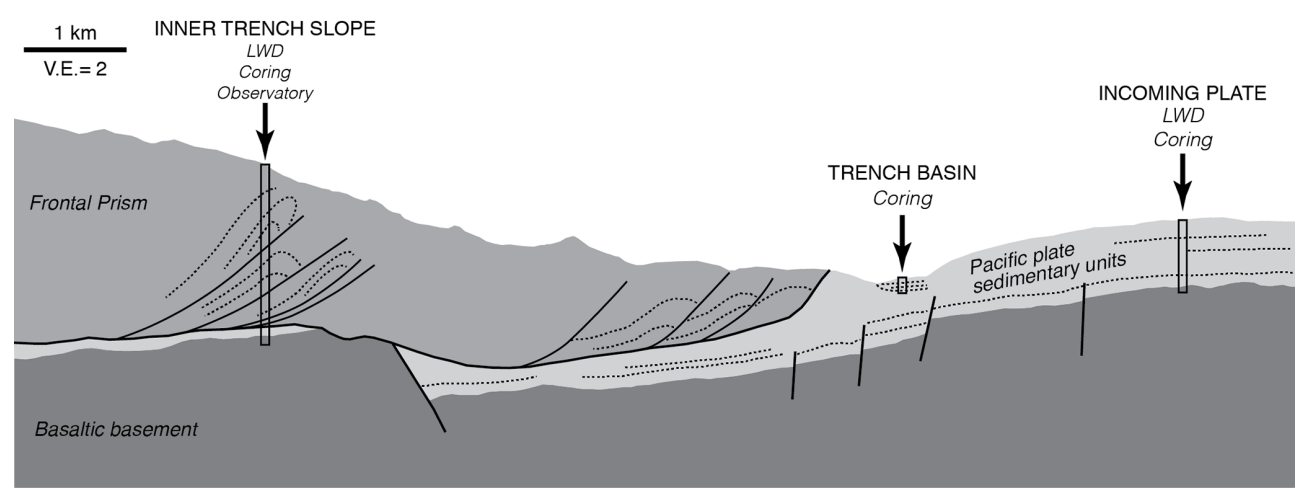

Figure 2. Schematic section through the frontal prism, trench and incoming section showing the framework for the two proposed trench normal transects, locations of the holes and list of target data for each hole (dashed lines represent possible bedding attitudes; solid lines are possible faults; structure based on Nakamura et al., 2013).

\subsection{Giant-piston coring to investigate the sedimentary record of earthquakes}

Following the SEP recommendation for a staged program, the workshop participants further agreed that addressing JTRACK objective 2 (i.e., develop and implement new methods for determining the recurrence of giant tsunamigenic earthquakes in the sediment record of the trench fill) requires an integrated 4-D approach that captures the sedimentary record of past earthquakes along the entire trench. The Japan Trench was identified by the workshop participants to be an area well predisposed for submarine paleoseismology according to criteria recently discussed in the open literature (i.e., Sumner et al., 2013; Atwater et al., 2014; Goldfinger et al., 2014). Sediment resuspension and redeposition related to the 2011 Tohoku-Oki earthquake has been documented and the respective deposits are preserved in basins formed by flexural bending of the Pacific plate. These basin are promising study areas for testing earthquake triggering of event deposits because the forearc slope is relatively simple, without large canyons, and Pleistocene sedimentation in hadal basins is not significantly affected by eustatic sea level changes. Results from conventional coring covering the last $\sim 1500$ years of the trench fill reveal good agreement between the sedimentary record and historically documented earthquakes. Therefore, the potential is high for submarine paleoseismology encompassing longer timescales accessible only by giant-piston coring and drilling.

A multi-platform, multi-coring strategy was developed during the workshop to utilize a combination of long, intermediate and short cores to be recovered from boreholes drilled by D/V Chikyu, mission-specific platform (MSP) giant-piston coring and conventional coring, respectively (Fig. 3). JTRACK paleoseismology research objectives are as follows:

I. Identify the sedimentological, physical, chemical, and biogeochemical proxies of event deposits in the sedimentary archive that allow for confident recognition and dating of past earthquakes (conventional \& MSP giantpiston coring).

II. Explore the spatial and temporal distributions of such proxies and investigate how they relate to fault characteristics and rupture areas of great earthquakes across the entire Japan Trench subduction system (conventional \& MSP giant-piston coring).

III. Elucidate the long-term recurrence pattern of events similar to the 2011 Tohoku-Oki earthquake (D/V Chikyu drilling).

The resulting earthquake catalog could be 10-100 times longer than current information on earthquake history. This catalog would help resolve the long-term recurrence pattern of great earthquakes at subduction zone margins, by testing the following two hypotheses:

- Great earthquakes have quasi-periodic recurrence owing to a seismic supercycle as predicted by a simple elastic rebound model.

- Great earthquakes occur randomly in time with a low, but on average, constant probability (Poissonian earthquake model).

\section{Outcomes of the workshop}

A full proposal for drilling in the Japan Trench was prepared after the workshop and was submitted to IODP in September 2014 (Proposal 835 Full - Japan Trench Tsunamigenesis). In parallel, a pre-proposal for a multi-coring approach by a MSP giant piston along an axis-parallel transect of the Japan Trench was developed following the workshop and was also submitted to IODP in September 2014 (Proposal 866 Pre Japan Trench Paleoseismology). Further work to investigate other portions of the Japan Trench margin that have caused 


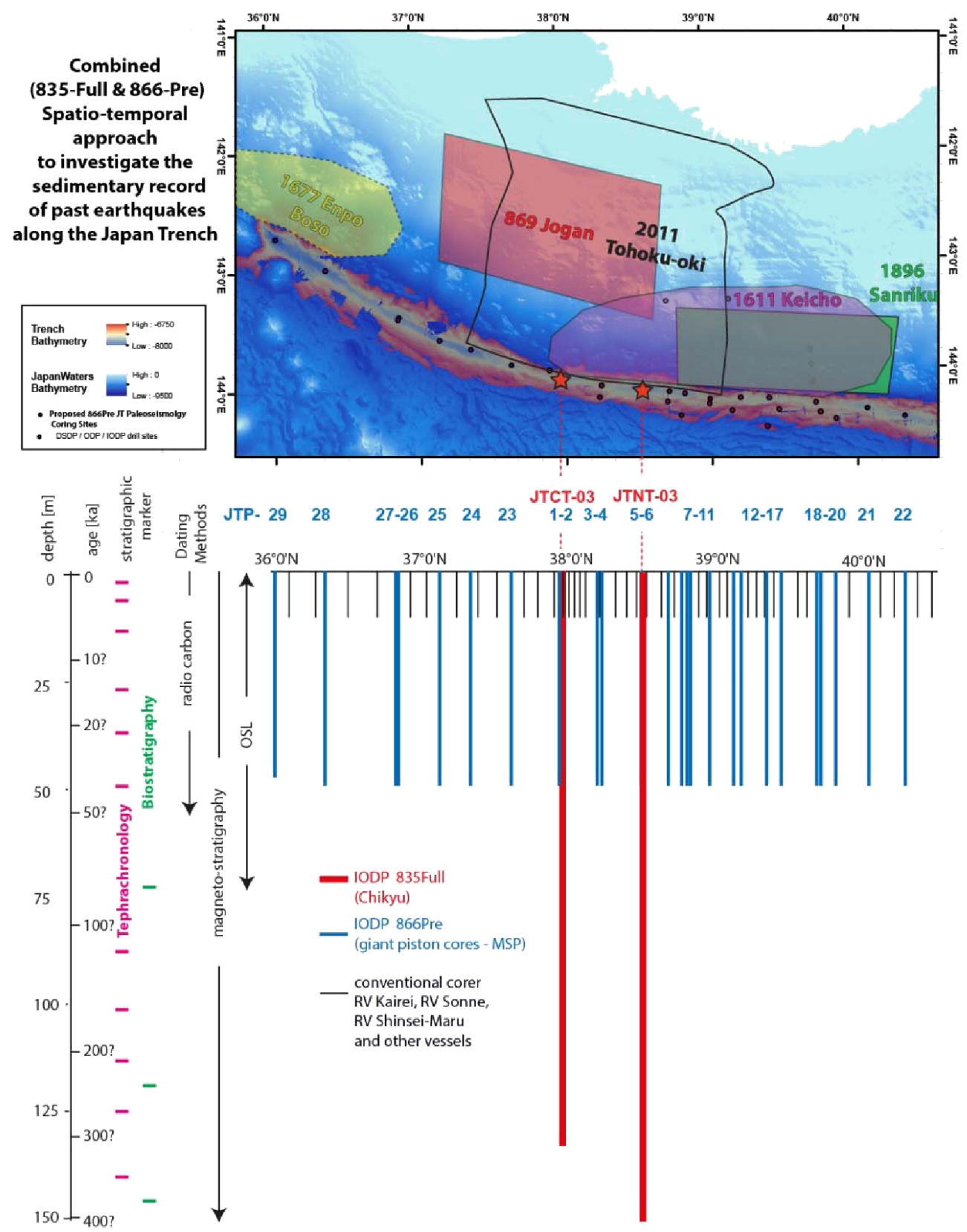

Figure 3. Graphic illustration of the integrated spatiotemporal research approach to investigate the sedimentary record of past earthquakes along the Japan Trench. The figure illustrates the schematic age-depth range (not to scale) and methods to establish absolute (upper part) and relative (lower part) recurrence of extreme event deposits along multiple, trench parallel coring transects by IODP mission-specific platform (MSP) giant-piston coring (JTP-Sites, Proposal 866 Pre) and accompanying short coring campaigns from conventional research vessels.

tsunamis will be planned in future proposals. More details regarding the workshop can be found on the CDex and USSSP websites.

Acknowledgements. We thank JAMSTEC, USSSP, CIB, JDESC and MagellanPlus for generously providing financial support for the JTRACK workshop and the attendees. Thanks also to JAMSTEC for hosting and providing assistance planning the workshop and Lisa McNeill for liaison with SEP and constructive input. We appreciate the constructive feedback from two anonymous reviewers that helped improved this work. Most importantly, thanks to the workshop attendees for their enthusiastic and insightful contributions.

Edited by: T. Wiersberg

Reviewed by: two anonymous referees 


\section{References}

Atwater, B. F., Carson, B., Griggs, G. B., Johnson, H. P., and Salmi, M. S.: Rethinking turbidite paleoseismology along the Cascadia subduction zone, Geology, 42, 827-830, 2014.

Bilek, S. L. and Lay, T.: Tsunami earthquakes possibly widespread manifestations of frictional conditional stability, Geophys. Res. Lett., 29, 1673, doi:10.1029/2002GL015215, 2002.

Chester, F. M., Mori, J., Eguchi, N., Toczko, S., and the Expedition 343/343T Scientists: Japan Trench Fast Earth- quake Drilling Project (JFAST), Proceedings of the IODP, vol. 343/343T, Integrated Ocean Drilling Program Management International Inc., doi:10.2204/iodp.proc.343343T.2013, 2013a.

Chester, F. M., Rowe, C. D., Ujiie, K., Kirkpatrick, J. D., Regalla, C., Remitti, F., Moore, J. C., Toy, V., Wolfson-Schwehr, M., Bose, S., Kameda, J., Mori, J. J., Brodsky, E. E., Eguchi, N., Toczko, S., Expedition 343, and 343T Scientists: Structure and composition of the plate-boundary slip zone for the 2011 Tohoku-oki earthquake, Science, 342, 1208-1211, doi:10.1126/science.1243719, 2013b.

Fujiwara, T., Kodaira, S., No, T., Kaiho, Y., Takahashi, N., and Kaneda, Y.: The 2011 Tohoku-Oki earthquake: Displacement reaching the trench axis, Science, 334, 1240, doi:10.1126/science.1211554, 2011.

Fulton, P. M., Brodsky, E. E., Kano, Y., Mori, J. J., Chester, F. M., Ishikawa, T., Harris, R. N., Lin, W., Eguchi, N., Toczko, S., Expedition 343, 343T, and KR13-08 Scientists: Low coseismic friction on the Tohoku Fault determined from temperature measurements, Science, 342, 1214-1217, doi:10.1126/science.1243641, 2013.

Goldfinger, C., Patton, J. R., Van Daele, M., Moernaut, J., Nelson, C. H., de Batist, M., and Morey, A. E.: Can turbidites be used to reconstruct a paleoearthquake record for the central Sumatran margin?: COMMENT, Geology, 42, p. e344, 2014.

Hashimoto, C., Noda, A., Sagiya, T., and Matsu'ura, M.: Interplate seismogenic zones along the Kuril-Japan trench inferred from GPS data inversion, Nat. Geosci., 2, 141-144, 2009.

Hatori, T., Irregular height deviation of the 1677 Enpo Boso-Oki tsunami, Eastern Japan, Historic Earthquakes, 19, 1-7, 2003 (in Japanese with English abstract).

Ide, S., Baltay, A., and Beroza, G. C.: Shallow dynamic overshoot and energetic deep rupture in the $2011 \mathrm{Mw}$ 9.0 Tohoku-Oki earthquake, Science, 332, 1426-1429, doi:10.1126/science.1207020, 2011.

Ito, Y., Tsuji, T., Osada, Y., Kido, M., Inazu, D., Hayashi, Y., Tsushima, H., Hino, R., and Fujimoto, H.: Frontal wedge deformation near the source region of the 2011 Tohoku-Oki earthquake, Geophys. Res. Lett., 38, L00G05, doi:10.1029/2011GL048355, 2011.
Kanamori, H., Miyazawa, M., and Mori, J.: Investigation of the earthquake sequence off Miyagi prefecture with historical seismograms, Earth Planets Space, 58, 1533-1541, 2006.

Kirkpatrick, J. D., Rowe, C. D., Ujiie, K., Moore, J. C., Regalla, C., Remitti, F., Toy, V., Wolfson-Schwehr, M., Kameda, J., Bose, S., and Chester, F. M.: Structure and lithology of the Japan Trench subduction plate boundary fault, Tectonics, 34, doi:10.1002/2014TC003695, 2015.

Lay, T., Ammon, C. J., Kanamori, H., Xue, L., and Kim, M. J.: Possible large near-trench slip during the $2011 \mathrm{Mw} 9.0$ off the Pacific coast of Tohoku Earthquake, Earth Planets Space, 63, 687-692, 2011.

Nakamura, Y., Kodaira, S., Miura, S., Regalla, C., and Takahashi, N.: High resolution seismic imaging in the Japan Trench axis area off Miyagi, northeastern Japan, Geophys. Res. Lett., 40, 1713-1718, 2013.

Sawai, Y., Namegaya, Y., Okamura, Y., Satake, K., and Shishikura, M.: Challenges of anticipating the 2011 Tohoku earthquake and tsunami using coastal geology, Geophys. Res. Lett., 39, L21309, doi:10.1029/2012GL053692, 2012.

Scholz, C. H.: Earthquakes and friction laws, Nature, 391, 37-42, 1998.

Sumner, E. J., Siti, M. I., McNeill, L. C., Talling, P. J., Henstock, T. J., Wynn, R. B., Djajadihardja, Y. S., and Permana, H.: Can turbidites be used to reconstruct a paleoearthquake record for the central Sumatran margin?, Geology, 41, 763-766, 2013.

Taira, A., Toczko, S., Eguchi, N., Kuramoto, S. I., Kubo, Y., and Azuma, W.: Recent scientific and operational achievements of D/V Chikyu, Geoscience Letters, 1, 1-10, doi:10.1186/21964092-1-2, 2014.

Tanioka, Y. and Gusman, A. R.: Reexaminatin of occurrence of large tsunamis after the analysis of the 2011 great Tohoku-oki earthquake, Zishin, 265-270, 2012 (in Japanese with English abstract).

Ujiie, K., Tanaka, H., Saito, T., Tsutsumi, A., Mori, J. J., Kameda, J., Brodsky, E. E., Chester, F. M., Eguchi, N., Toczko, S., Expedition 343, and 343T Scientists: Low Coseismic Shear Stress on the Tohoku-Oki Megathrust Determined from Laboratory Experiments, Science, 342, 1211-1214, doi:10.1126/science.1243485, 2013.

Wang, K. and $\mathrm{Hu}, \mathrm{Y} .:$ Accretionary prisms in subduction earthquake cycles: The theory of dynamic Coulomb wedge, J. Geophys. Res., 111, B06410, doi:10.1029/2005JB004094, 2006.

Yue, H. and Lay, T.: Inversion of high-rate (1 sps) GPS data for rupture processes of the 11 March 2011 Tohoku earthquake (Mw 9.1), Geophys. Res. Lett., 38, L00G09, doi:10.1029/2011GL048700, 2011. 